\title{
Prospective Primary School Teachers' Competence for the Cognitive Analysis of Students' Solutions to Proportionality Tasks
}

\author{
María Burgos $(\mathbb{D} \cdot$ Juan D. Godino
}

Received: 26 September 2020 / Accepted: 30 September 2021 / Published online: 25 October 2021

(C) The Author(s) 2021

\begin{abstract}
In order to foster the learning of mathematics, the teacher must be able to analyse and assess the students' mathematical activity. The explicit recognition of objects and processes involved in mathematical practices is a competence that the teacher should develop. This cognitive analysis competence allows the teacher to understand the processes of mathematical learning, to foresee conflicts of meanings and to establish different possibilities for institutionalising the mathematical knowledge involved.

In this article we present the results of the evaluation phase of a training intervention with eighty-eight prospective primary school teachers, which aims to promote and assess the competence for the cognitive analysis of students' solutions to proportionality tasks. To this end, we proposed the prospective teachers to interpret different students' solution strategies for a problem, recognise the mathematical elements (languages, concepts, propositions, procedures and arguments) put at stake in each strategy, and to analyse the algebraic character of the mathematical practices involved in them. The results reveal the prospective teachers' limitations for the analysis and assessment of non-usual resolution strategies, the identification of key mathematical objects and the discrimination of arithmetic and algebraic activity in the students' solutions. The improvement of the results requires the following actions: to allow prospective teachers to become acquainted with different forms of reasoning that can be applied in proportionality situations, delve more deeply into the algebraic character of mathematical activity, and extend the number and variety of situation problems that prospective teachers can analyse and discuss.
\end{abstract}

María Burgos $(\bowtie) \cdot$ Juan D. Godino

Department of Didactic of Mathematics, Facultad de Ciencias de la Educación, Campus Universitario

de Cartuja, University of Granada, 18071 Granada, Spain

E-Mail: mariaburgos@ugr.es

Juan D. Godino

E-Mail: jdgodino@gmail.com 
Keywords Proportionality · Teacher's education · Onto-semiotic approach · Algebraization levels · Cognitive analysis

\section{Die Kompetenz angehender Grundschullehrkräfte zur kognitiven Analyse von Schülerlösungen zu Proportionalitätsaufgaben}

Zusammenfassung Um das Erlernen von Mathematik zu fördern, müssen Lehrkräfte in der Lage sein, die mathematischen Aktivitäten ihrer Schülerinnen und Schüler $\mathrm{zu}$ analysieren und zu bewerten. Das explizite Erkennen von Objekten und Prozessen, die an mathematischen Praktiken beteiligt sind, ist eine Kompetenz, die Lehrkräfte entwickeln sollten. Diese kognitive Analysekompetenz ermöglicht es Lehrkräften, Prozesse des mathematischen Lernens zu verstehen, Bedeutungskonflikte vorauszusehen und verschiedene Möglichkeiten zur Verfestigung mathematischen Wissens zu finden.

In diesem Artikel stellen wir die Ergebnisse der Evaluationsphase einer Fortbildungsmaßnahme mit 88 angehenden Grundschullehrkräften vor, die darauf abzielt, die Kompetenz zur kognitiven Analyse von Schülerlösungen zu Proportionalitätsaufgaben zu fördern und zu bewerten. Zu diesem Zweck sollten angehende Lehrkräfte verschiedene Lösungsstrategien von Schülerinnen und Schülern für eine Aufgabe interpretieren, die mathematischen Elemente (Sprache, Konzepte, Sätze, Verfahren und Argumente) erkennen, die in den verwendeten Strategien zum Tragen kamen, und den algebraischen Charakter der beinhalteten mathematischen Praktiken analysieren. Die Ergebnisse zeigen die Grenzen der angehenden Lehrkräfte bei der Analyse und Bewertung unüblicher Lösungsstrategien, der Identifizierung wichtiger mathematischer Objekte und der Unterscheidung von arithmetischen und algebraischen Aktivitäten in den Schülerlösungen auf. Zur Verbesserung der Ergebnisse sind folgende Maßnahmen erforderlich: Die angehenden Lehrkräfte sollten verschiedene Formen der Argumentation kennenlernen, die in Proportionalitätssituationen angewandt werden können, den algebraischen Charakter der mathematischen Aktivität vertiefen und die Anzahl und Vielfalt der Situationsprobleme, die die angehenden Lehrkräfte analysieren und diskutieren können, erweitern.

Schlüsselwörter Proportionalität · Lehrerausbildung · Onto-Semiotik Ansatz · Algebraisierungsstufen · Kognitive Analyse

\section{Introduction}

The importance of the study of ratio, proportion and proportionality in the Primary and Secondary Education curriculum is supported by the decisive role that diverse researchers in mathematics education give to proportional reasoning for developing students' algebraic thinking (Lesh et al. 1988; Van Dooren et al. 2010). However, and despite the importance of this content, there is much evidence that both prospective and in-service teachers have difficulties in understanding and teaching some of the proportional reasoning components (Ben-Chaim et al. 2012; Berk et al. 2009; Buforn et al. 2018; Livy and Vale 2011; Riley 2010; Rivas et al. 2012), as well as to interpret 
the responses of primary education students when they solve proportionality tasks. In particular, prospective teachers struggle to interpret the responses of primary education students when they solve proportionality tasks, and to consider the way in which students seem to understand proportionality in order to take decisions (Buforn et al. 2020; Fernández et al. 2013; Son 2013).

Although the analysis of students' thinking is highlighted as one of the central tasks of mathematics teaching, identifying the mathematical ideas inherent to the strategies that a student uses during mathematical problem solving could be difficult for the teacher (Fernández et al. 2013, p. 442). Researchers such as Bartell et al. (2013) and Son (2013) suggest that, on the one hand, a limited knowledge of mathematical content makes it difficult for teachers to interpret the students' answers in order to make pertinent decisions and, on the other hand, the content knowledge is not enough for the teachers to recognise the students' mathematical comprehension. Therefore, teachers' preparation should take into account the development of didactic-mathematical knowledge and competences regarding this topic when designing and implementing specific training interventions. Along this line, several research works have focused on providing contexts to develop the competence of interpreting students' mathematical understanding in teacher education programs (Barnhart and van Es 2015; Jacobs et al. 2010; Simpson and Haltiwanger 2017; Son 2013). As suggested by Ivars et al. (2018), this competence requires identifying those relevant mathematical elements (discerning details) in students' answers and recognising relationships between identified elements and characteristics of students' mathematical thinking (interpreting students' mathematical thinking by taking into account specific mathematical elements).

Our proposal to address the didactic-mathematical knowledge and competences regarding proportional reasoning in teacher education is to articulate proportional reasoning with algebraic reasoning. The importance of proportionality as an access route to early algebraic reasoning (Van Dooren et al. 2010) led us to analyse proportional reasoning by means of the algebraic character of the mathematical practices involved in solving proportionality tasks. To perform this analysis, we take into account some theoretical tools from the Onto-Semiotic Approach (OSA) of mathematical knowledge and instruction (Godino and Batanero 1996; Godino et al. 2007). In particular, we use the onto-semiotic configuration of practices, objects and processes that facilitates the description and detailed analysis of the mathematical practices required to solve a problem, and the algebraization levels model (Aké et al. 2013; Godino et al. 2014), that allows teachers to establish links between the different (arithmetic, proto-algebraic and algebraic-functional) meanings of proportionality. Some research developed within the OSA framework (Burgos et al. 2018, 2019; Burgos and Godino 2018), was mainly concerned with epistemic aspects of the didactic and mathematical knowledge, and showed a deficient and biased conception of the nature of the elementary algebraic reasoning involved in proportionality tasks.

This article focuses on assessing prospective primary school teachers' competence for the cognitive analysis of students' solutions to proportionality tasks ${ }^{1}$. This

\footnotetext{
${ }^{1}$ The research presented refers to the German (early) secondary mathematics curriculum.
} 
competence is interpreted as the ability to: (a) attend students' solution strategies in a problem, (b) split students' resolutions in elementary practices, (c) identify the intervening object (languages, concepts, propositions, procedures and the argumentation of these objects), and (d) recognise different algebraization levels of students' mathematical practices. We think that describing the system of operative and discursive practices performed by students (personal meaning), and determining the configurations of objects and processes emerging from the system of such practices (cognitive configuration), can help to "identify the mathematical elements of problems that foster proportional reasoning breaking down the mathematics that define the problem and recognising the manner in which the mathematical elements that characterize the problem are present or not in the student's answer" (Llinares 2013 , p. 80). Besides, the identification of the algebraization levels involved in actual solutions to proportionality tasks given by primary school students (that is, the recognition of the degree of generality of the objects, the treatment that is applied to these objects, as well as the types of languages used) reveals the overlapping of proportional reasoning and algebraic reasoning.

\section{Background and Theoretical Framework}

The study of the type of didactic and mathematical knowledge and competences that teachers should have in order to manage the students' learning process has generated several models that intend to characterize such teachers' knowledge and competences (Ball and Bass 2009; Blömeke et al. 2015; Chapman 2014; Depaepe et al. 2020; Hill et al. 2008). In this research we adopt the teacher's Didactic-Mathematical Knowledge and Competence (DMKC) model (Breda et al. 2017; Godino et al. 2017) developed within the OSA. In this model, the mathematical dimension of teacher's knowledge refers to the knowledge that enables teachers to solve mathematical problems or tasks that are typical of the educational level in which they will teach (common mathematical knowledge) and link the mathematical objects of such level to mathematical objects that will be studied at higher levels (expanded mathematical knowledge). These two subcategories reinterpret the common content knowledge (Hill et al. 2008) and the horizon knowledge (Ball and Bass 2009), respectively, which are "based on the need to settle the knowledge that a mathematics teacher should possess on specific topics to be taught at some school grades" (PinoFan et al. 2015, p. 1433). The didactical dimension of the DMKC model (Breda et al. 2017; Godino et al. 2017) proposes six subcategories of teacher's knowledge: epistemic (institutional content meanings), ecological (aligning tasks according to institutional mandatory curriculum), cognitive (understanding student's thinking), affective (reacting to anguish, indifference, anger, etc., manifested by students), interactional (identifying and answering to students' conflicts and interactions), and mediational (choosing the best suitable resources for teaching). These categories of the teacher's didactic-mathematical (or specialized) knowledge provide a more detailed perspective than the one assumed in Shulman's PCK model (Pedagogical Content Knowledge; Shulman 1986) or Ball's MKT model (Mathematical Knowledge for Teaching; Hill et al. 2008). Within these models, knowledge of content 
and teaching combines knowing about teaching and knowing about mathematics, including knowledge of the design of instruction, such as the knowledge governing the choice of examples to introduce a content item and those used to take students deeper into it (epistemic, mediational and interactional facets in DMKC model). Knowledge of content and students, combine knowing about mathematics and knowing about students. It includes knowledge of common student conceptions and misconceptions about particular mathematical content as well as the interpretation of students' emerging and incomplete thinking (cognitive facet in the DMKC model) (Scheiner et al. 2019).

One of the fundamental aspects of the DMKC model is the interconnectedness of the notion of teachers' knowledge with that of their competence. Teachers' competence is understood as the ability or capacity to address the basic didactic problems involved in teaching and learning mathematics, in particular, to provide appropriate responses to real classroom situations, such as assessing students' responses and making consequent decisions. It is considered that such effective action requires the mastery and application of specific theoretical tools by teachers. It does not include the affective motivational dispositions that underlie that behaviour, contrary to the multidimensional, global and psychometric notion of professional competence developed by Blömeke et al. (2015) and Depaepe et al. (2020). The affective component is a specific facet of the didactic-mathematical knowledge in the DMKC model and refers to beliefs, affects and dispositions towards mathematics in the case of mathematics instruction processes, or towards mathematics and its teaching in teacher education processes. That is, the teachers should take into account the affective component (attitudes, emotions, dispositions, beliefs) in the processes of learning mathematics by their students; the teachers' educator should be aware of the affective component in teachers' education processes, referring in this case to teachers' beliefs and affects about mathematics and its teaching.

In this research work we focus our attention mainly on assessing the prospective teachers' cognitive analysis competence, which allows teachers to understand the ways of thinking, and to recognise personal meanings, misconceptions, conflicts and errors that arise from the process of problem solving. Cognitive analysis competence involves:

a) attending students' solution strategies in a problem, analysing whether the procedures and arguments are correct;

b) splitting students' resolutions into elementary practices;

c) identifying the objects: languages (natural, iconic, diagrammatic, symbolic ...), concepts, propositions, procedures and arguments, intervening in those practices;

d) assigning the algebraization levels to students' solutions, based on the types of representations used, the generalization processes involved, and the analytical calculation performed in their mathematical activity.

In particular, we address the following research questions:

(1) How do prospective teachers analyse and justify the degree of correctness of the solutions given by primary school students to proportionality problems? 
(2) What mathematical elements (languages, concepts, properties, procedures and arguments) do prospective teachers identify in the solutions proposed by primary school students?

(3) Based on this identification, are prospective teachers able to assign levels of algebraic reasoning to the different solutions analysed?

To develop the teachers' cognitive analysis competence, the OSA provides specific theoretical and methodological tools that are briefly outlined below. In particular the pragmatic meaning of a mathematical object and the configuration of practices, objects and processes (Sect. 2.1) allow to describe the system of operative and discursive practices performed by the students while problem solving. The analysis of students' mathematical practices by means of their algebraic character, allows prospective teachers to carry out a microscopic analysis of mathematical activity, closely looking at the network of concepts, languages, procedures and arguments that are involved in different mathematical practices and how they relate to each other. To this end, we include in Sect. 2.2. the elementary algebraic reasoning model of Aké et al. (2013). Finally, in Sect. 2.3 the algebraization levels are applied to the analysis of the mathematical practice systems linked to proportionality tasks. The recognition of the algebraization levels associated to the mathematical practices carried out by students while solving proportionality tasks, allows teachers to establish links between the different (arithmetic, proto-algebraic and algebraic-functional) meanings of proportionality and to become aware of the progressive degrees of cognitive complexity associated with proportional reasoning.

\subsection{Pragmatic Meaning and Onto-Semiotic Configuration}

From the pragmatist point of view of the didactic-mathematical knowledge assumed by the OSA, the notion of mathematical practice, considered as any action intended to solve a problem or perform a task, determines the starting point for the analysis of mathematical activity (Font et al. 2013). The OSA proposes two levels to perform this analysis:

1. Describing the system of operative and discursive practices (actions) that the subject performs (pragmatic meaning).

2. Describing the network of objects and processes that intervene and emerge from the system of such practices (onto-semiotic configuration).

In this framework, the term object is used in a broader sense to refer to any entity that in some way is involved in mathematical practice and that can be distinguished from others; the pragmatic meaning of an object is understood as the system of practices associated with the field of problems from which the object emerges at a given moment.

In order to conduct a more systematic analysis of the mathematical practices developed regarding certain problems, the OSA introduces a typology of primary mathematical objects arising in the system of practices: languages (terms, expressions, notations, graphs) in their different registers (written, oral, gestural, etc.), concepts (introduced using definitions or descriptions), propositions (statements about 
concepts), procedures (algorithms, operations, calculus techniques) and arguments (statements used to validate procedures or explain propositions). These objects do not appear isolated, but they are interconnected with each other forming onto-semiotic configurations of practices, objects and processes.

When the aim is to analyse the expert mathematical practices involved in solving a problem, this analysis is considered as epistemic (institutional meaning, epistemic configuration). However, when the goal is to examine the activity developed by students to solve a problem, as in the case of the present research, we will use the term cognitive analysis (personal meaning, cognitive configuration). Hence, teachers' cognitive analysis competence supposes, in particular, the ability to identify and analyse practices, objects and processes involved in the students' solutions to mathematical tasks, that is, to describe the cognitive configurations that students develop when solving the proposed problems. As we see below, the study of the algebraization levels, defined in terms of the objects, meanings and processes emerging in the mathematical practices, allows a "finer" analysis of the mathematical activity that a subject performs when solving a specific problem.

\subsection{Elementary Algebraic Reasoning and Algebraization Levels}

We assume the point of view of authors such as Kieran (2004) about the nature of algebraic reasoning, who identify it as one that allows analysing the relationships between quantities, recognising the structure of a situation, studying change, generalizing, testing or making predictions, and justifying situations that involve mathematical objects.

Within the OSA framework a characterization of algebraic reasoning for Primary Education has been proposed in which three levels of reasoning are distinguished (Aké et al. 2013; Godino et al. 2014), establishing criteria to identify purely arithmetic mathematical activity and distinguish it from progressive levels of algebraization ${ }^{2}$. The criteria to discriminate the algebraization levels rely on the presence of intensive algebraic objects (results of generalization processes), the transformations applied to these objects and the type of language used. Level 0 indicates the absence of algebraic characteristics (arithmetic nature of mathematical activity) and level 3 means a clear algebraic activity (syntactically guided reasoning and actions on generalizations expressed in conventional symbol systems). The intermediate levels of proto-algebraic activity (levels 1 and 2) are in line with the proposal of early algebra (Carraher and Schliemann 2007), and are included to discriminate from other stable or consolidated forms of algebraic reasoning:

Level 0 Operations with intensive objects of first degree of generality are carried out, using natural, numeric, iconic and gestural languages.

\footnotetext{
2 The algebraization levels are not assigned to the tasks themselves, which can be solved in different ways, being able to bring into play a different algebraic activity, nor are they assigned to the individuals, who can develop solutions that involve objects or processes corresponding to different algebraization levels for the same problem-situation.
} 
Level 1 Use of intensive objects of the second degree of generality, whose generality is explicitly recognised by natural, numerical, iconic or gestural languages, are involved; properties of the algebraic structure of the number set $\mathbb{N}$, and equality as equivalence. Literal-symbolical representation can intervene referring to the recognised intensive objects, but no operation is performed with those objects.

Level 2 Literal-symbolical representations are used to refer to recognised intensive objects linked to spatial and contextual information; equations of the form $A x+B=$ $C(A, B, C \in \mathbb{R})$ are solved. In the functional setting, a general rule is expressed.

Level 3 Symbols are used analytically, without referring to contextual information. Operations with indeterminates or variables are carried out; equations of the form $A x+B=C x+D(A, B, C, D \in \mathbb{R})$ are solved.

We include Fig. 1 in order to exemplify the emergence of objects in the sequence of practices in solving a proportionality task and the related algebraization levels.

Teachers' recognition of the different algebraization levels while solving mathematical tasks or when analysing students' solutions to problems related to a specific notion, in particular, proportionality, is considered a key aspect of the DMKC model since it allows to understand its semiotic complexity and explaining the learning difficulties.

\subsection{Proportional Reasoning}

Proportional reasoning is understood as the ability to establish multiplicative relationships between two quantities and to extend this relationship to another pair of quantities (Lamon 2007). This places proportional reasoning as a precursor to algebraic thinking (Langrall and Swafford 2000) and functional thinking (Lichti and Roth 2019).

Empirical research indicates that students use many different strategies to solve proportionality problems: building up, doubling, unit-rate, factor of change, cross multiplication (Cramer and Post 1993; Kurt 1992; Lamon 2007; Misailidou and Williams 2002). The strategies used are affected by whether the problem context is familiar to the student or not, the placement of the unknown value, and the nature of the numerical relationships, that is, the presence or absence of integer ratios, the size of the ratios or the numbers involved (Tourniaire and Pulos 1985; Misailidou and Williams 2003).

Langrall and Swafford (2000) or Misailidou and Williams (2003) proposed different levels of students' proportional reasoning in terms of the tasks in which students may or may not succeed. However, authors such as Modestou and Gagatsis (2010) consider that proportional reasoning does not only imply the success in solving a range of proportional problems, but it also involves handling verbal and arithmetical analogies, as well as the awareness of discerning non-proportional situations from other situations. Lamon (2007) suggests that "the reasoning aspect of proportional reasoning entails recognition of the constant ratio between elements of the same measure space and recognition of the functional relationship between measure spaces" (p. 638). 
Problem-situation: Divide 40 nuts between Juan and Saúl in a ratio of 3:5. How many does each child receive? Solution 1 Part-whole (proto-algebraic, algebraization level 1)

Sequence of elementary practices to solve the task Objects referred in the practices

1. Since the sharing ratio of the nuts between Juan and Saúl is 3:5, of every 8 nuts that they receive jointly, Juan receives 3 , that is, Juan will receive $3 / 8$ of the nuts to be shared.

2. That is, Juan receives $\frac{3}{8} \times 40=15$ nuts.

Concepts: sharing, ratio, fraction

Proposition P1: Juan will receive $3 / 8$ of the nuts to be shared.

Argument A1: The sharing ratio of the nuts between Juan and Saúl is 3:5

Concepts: whole, part, fraction

Proposition P2: Juan receives 15 nuts.

Procedure: Apply the fraction as an operator to the amount of total nuts.

Argument A2: based on the operator meaning of fraction.

3. To know how many nuts Saúl will receive, we Proposition P3: Saúl will receive 25 nuts.

only have to subtract from the total number of nuts,

Procedure: Subtraction operation.

the nuts that Juan receives, that is, $40-15=25$.

Arguments A3: If Juan receives a quantity of nuts, Saul will receive the rest up to 40 which is the total to be distributed.

A general relation is established between the ratio of nuts that each child receives and the total nuts to be shared, although this rule is stated with arithmetic and natural language. This strategy solution requires to recognise the use of the fraction as operator which applied on the initial number of nuts allows us to find the final number of nuts that corresponds to one of the children. The mathematical activity carried out involves level 1 of algebraic reasoning.

\begin{tabular}{|c|c|}
\hline \multicolumn{2}{|c|}{ Solution 2 Missing value (proto-algebraic, algebraization level 2) } \\
\hline Sequence of elementary practices to solve the task & Objects referred in the practices \\
\hline $\begin{array}{l}\text { 1. Since the sharing ratio of the nuts between Juan } \\
\text { and Saúl is } 3: 5 \text {, of every } 8 \text { nuts that they receive } \\
\text { jointly, Juan receives } 3 \text {. }\end{array}$ & $\begin{array}{l}\text { Concepts: sharing, ratio, fraction } \\
\text { Proposition P1: Of every } 8 \text { nuts that they receive } \\
\text { jointly, Juan receives } 3 \text {. }\end{array}$ \\
\hline
\end{tabular}
jointly, Juan receives 3 .

Argument A1: The sharing ratio of the nuts between

2. The relation between the magnitudes number of nuts that Juan receives, and total number of distributed nuts is of direct proportionality.

3. Hence, the ratios of the corresponding quantities are the same: $3 / 8=x / 40$; where $x$ is the number of Juan and Saúl is 3:5

Concepts: magnitude, direct proportionality.

Proposition P2: Statement of practice 2.

Argument A2: The sharing ratio determines direct proportionality relationships between the total number of nuts and the amount each child receives. Concepts: ratio, proportion, unknown, equation Procedure: Establish the proportional equation. nuts that Juan receives.

3. Therefore $3 \times 40=8 \times x$, and thus $x=(3 \times 40) / 8=15$.

Proposition P3: The proportion 3/8 = x/40; where $x$ is the number of nuts that Juan receives, can be stated.

Argument A3: The relation between the number of nuts that Juan receives and the total nuts distributed is of direct proportionality

Procedure: Solve the unknown.

Argument: In any proportion the product of the means is equal to the product of the extremes (Cross product property)

4. From above, Juan receives 15 nuts and Saúl, Proposition P4: Juan receives 15 nuts and Saúl receives 25 nuts.

Procedure: Subtraction operation

Arguments A4: The obtained value of the unknown in the proportional equation gives the number of nuts Juan will receive.

With this technique, it is necessary to identify the quantities involved and to recognise the direct proportionality relationship between the magnitudes. The equality of ratios of the corresponding amounts and the equality of cross-products in a proportion to get the unknown value must be evoked. Hence the algebraization activity that is carried out is level 2 , since the unknown value appears in a member of the equation established by the proportion.

Fig. 1 Ontosemiotic configuration and algebraization level in solving a proportionality task 
As explained in Sect. 2.1, in the OSA framework the (institutional or personal) meaning of a mathematical object is identified with the system of operational and discursive practices associated with the field of problems from which the object emerges (Godino and Batanero 1996). Hence, the application of the algebraization levels to the practice systems linked to proportionality tasks, provides criteria to distinguish categories of meanings in the progressive construction of proportional reasoning ${ }^{3}$.

- The arithmetic meaning (algebraization level 0 ) is characterized by the application of arithmetic calculation procedures to particular numerical values.

- The proto-algebraic meaning (see Fig. 1) is focused on the notion of proportion, so that the recognition of the unit value in a unit reduction procedure, and the use of diagrammatic representations of solutions can be described as proto-algebraic of level 1. On the other hand, the solution of a problem of missing value, based on the use of ratios and proportions, yields the establishment of the proportional equation or rule of three, and its resolution through cross multiplication. The algebraization activity that is carried out in this case is proto-algebraic of level 2, since the unknown appears clear in a member of the equation that is established $(A x=B)$.

- Algebraic-functional meaning (algebraization level 3) is characterized by the application of the notion of linear function and resolution techniques based on the properties of these functions.

\section{Method}

This study is part of a research project aimed to design, implement and evaluate formative interventions to develop teachers' didactic-mathematical knowledge and competence related to proportional reasoning. In particular, the aim of the specific intervention described in this paper is to promote prospective teachers' competence for the cognitive analysis of students' solutions to proportionality tasks.

The methodological approach adopted is that of didactic engineering, in our case understood in a generalized sense, as proposed by Godino et al. (2013). This approach extends the traditional conception of didactical engineering (Artigue 1989) in the direction of research based design (Cobb et al. 2003) proposing four phases in the research cycle: (1) preliminary study; (2) design of the experiment; (3) implementation; (4) evaluation or retrospective analysis. Due to space limitations, we cannot present in detail the whole research cycle and we focus our attention on the implementation and evaluation phases.

\footnotetext{
3 Within the OSA framework it is preferred to speak of reasoning when describing the operative and discursive practices that are performed to solve a task, whether they are performed by an epistemic or cognitive subject. In any case, in the realization of such practices, non-ostensive objects (mental or ideal) intervene reflecting the thought (understanding) that necessarily accompanies them.
} 


\subsection{Context and Participants}

The formative experience was carried out with a group of 88 students for teacher from the third year of the Primary Education degree at the University of Granada (Spain). The training experience was implemented in the framework of the course "Design and Development of Mathematics Curriculum in Primary Education". The first author was the regular teacher of the course.

During their undergraduate studies (four years training), these prospective teachers received specific preparation on the epistemic, cognitive, instructional and curricular aspects of teaching mathematics. At the end of their first academic year, the prospective teachers are supposed to create and solve mathematics problems using different strategies in a wide variety of situations and contexts, and to know and articulate the main concepts, properties and procedures that form the primary education mathematics curriculum. In the second year, students for teacher received specific teaching on the foundations of Didactics of Mathematics, particularly in: cognitive aspects (mathematical learning, errors and difficulties) and instructional aspects (tasks, materials and resources). Finally, during the third year of study, when this intervention was developed, trainee teachers must deepen and apply the knowledge acquired in the preceding years to develop teaching units.

In this paper, we analyse the information collected from the notes of the observer/ researcher and the prospective teachers' written responses to part of the assessment task proposed at the end of the formative intervention.

\subsection{Implementation of the Formative Process}

First, a two-hour session was held in which the characteristics of the elementary algebraic reasoning, and the model of algebraization levels of mathematical activity proposed by Godino et al. (2014) were presented. The aim of this session was to reflect and make deeper distinction of types of algebraic objects and processes in school mathematics tasks, and to assign levels of algebraic reasoning involved in the mathematical activity carried out when solving various tasks, some of which were related to proportionality situations. We explained to the prospective teachers the different types of mathematical objects and processes, with emphasis on those of an algebraic nature: binary relations, operations and their respective properties, performed over elements of various sets of objects, and functions, as well as the processes of generalization-particularization and representation. Then, we explained how through these elements it is possible to classify the algebraic character of a mathematical practice, and how the algebraization levels are associated with different pragmatic meanings of proportionality. More specifically, since it is expected to develop the analytical competence of the practices developed by elementary students in the prospective teachers, Brousseau's puzzle situation (Brousseau 1997) was used to present: 1st the epistemic analysis of possible solutions with different algebraization levels, and 2nd the cognitive analysis of the answers given to the task by students of 5th year of primary education, providing prospective teachers with the possibility of reflecting on the presence of algebraic objects in students' 
The answers given by some primary school students to some problems are included in the Annex.

a) Do you think that the responses (procedures and arguments) given by the students are correct? Justify your answer.

b) Identify the types of languages (natural, iconic, diagrammatic, symbolic ...), concepts, properties, procedures and arguments that you recognise in those solutions.

c) Assign with justification the algebraization levels to their solutions.

Fig. 2 Task proposed to the prospective teachers to assess the level of cognitive analysis competence

productions. This was the prospective teachers' first contact with the OSA tools, analysis of mathematical objects, and epistemic and cognitive configurations.

In the next session (also of two hours), the prospective teachers had to work in teams to respond to similar questions that were used in the assessment task. In the proposed tasks, we displayed the solutions given by two students of 5th and 6th grade of primary education to two problems (two responses for each situation). These problems had been used in the formative session to exemplify the description of the epistemic configurations and the recognition of algebraization levels involved in proportionality problems.

In the third session, the prospective teachers worked individually on the tasks proposed as a final assessment instrument, allocated to identify and develop certain aspects of didactic-mathematical knowledge regarding proportionality. It is expected that prospective teachers can analyse the answers given by primary school students to proportionality problems, justifying the degree of correctness, identifying the mathematical objects involved in the solutions, and assigning, in relation to these objects, the algebraization levels to the mathematical practices developed by students (Fig. 2). The results of the analysis of the answers given by the participants to these tasks are those presented in this paper.

Figs. 3, 4 and 5 below show the answers of primary students (3rd, 5th and 6th grade) to three different problems (Problem 1, Problem 2 and Problem 3, respectively) delivered with the task described in Fig. 2. The six responses of primary school students have been chosen from a larger sample to allow the prospective teachers' reflection on the complexity of the algebraization levels, and the role that the presence of literal symbols, the analytical calculation developed with them and the degree of generality of the intervening objects, play in the algebraic character of a mathematical practice. In total, the prospective teachers had to evaluate six solutions, two for each of the following problems:

Problem 1 Laura and Sofia want to paint their rooms of the same color. Laura mixes 3 cans of yellow paint and 6 of red paint. If Sofia has used 7 cans of yellow paint, how many cans of red paint will she need? Explain your answer. 


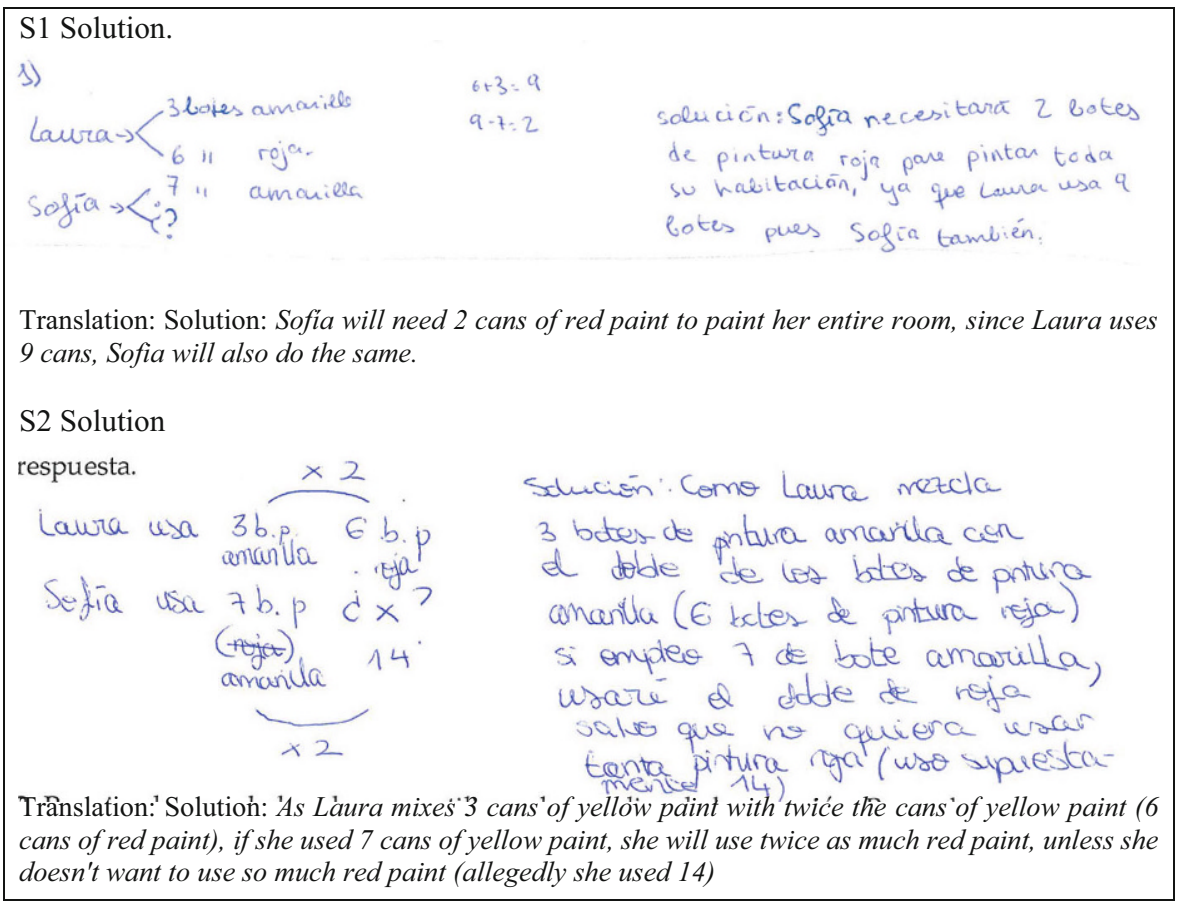

Fig. 3 Responses of students S1 and S2 to problem 1

Problem 2 With three kilograms of corn my hens eat for 6 days. How many kilograms of corn will I need to feed them for 30 days? Explain your answer.

Problem 3 Two friends, Laura and Daniel, want to buy a box of 20 chocolates. For its purchase, Laura has given 6 euros and Daniel has given 4 euros. The chocolates will be distributed, taking into account the amount of money that each one has contributed for the purchase.

a) What is the price of each chocolate? Explain how you have found it out.

b) How many chocolates would correspond to each one? Explain how you reached the answer.

These problems are different from those that were used in the previous instruction and in the teamwork sessions. The first two problems correspond to missing value proportional situations. The first one (inspired by Misailidou and Williams 2003) allowed us to find a wrong solution by a 6th grade primary school student (S1) using the constant sum strategy already identified by research on this topic (Misailidou and Williams 2002). The prospective teachers are expected to identify and justify the student's error. In the second solution, the prospective teachers should recognise the role of the literal symbol to denote an unknown number, for which no analytical calculation is performed (hence, there is no algebraic activity involved). 


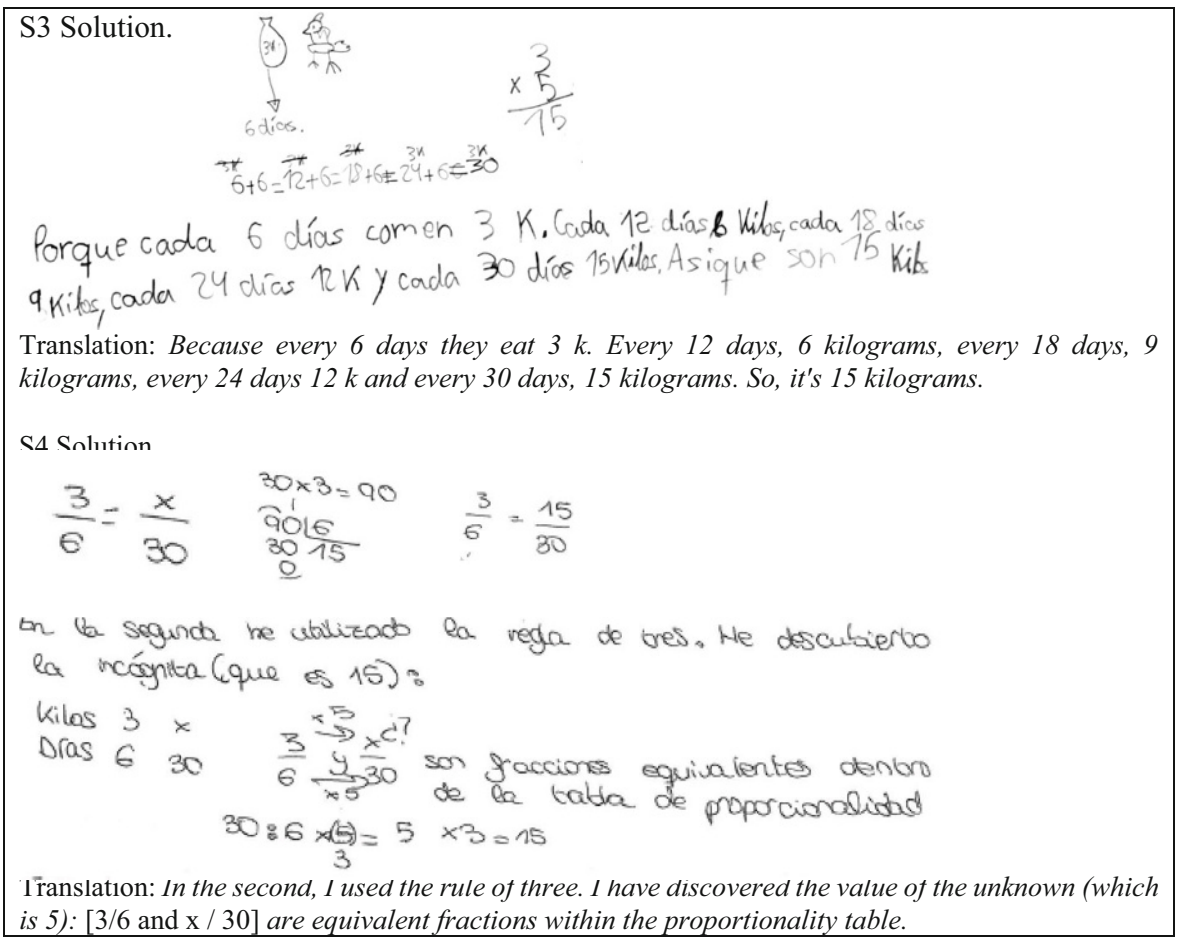

Fig. 4 Responses of students S3 and S4 to problem 2

For the second problem, the two answers provided by primary school students that are included are correct. One of them (S3) developed by a 3rd grade primary education student follows an arithmetic strategy. We intend to evaluate the prospective teachers' competence to analyse non-usual strategies resolution and to judge informal arguments to proportionality problems. The other one was drawn up by a 6th grade student (S4) who explains the proportionality relationship and solves it by means of a proto-algebraic strategy (cross multiplication). In this case, the prospective teachers are expected to appreciate the role of symbolic language and the type of transformations applied.

The third problem raises a situation of proportional distribution. The students' answers (one from the 5 th grade and the other from the 6th grade primary education) propose different strategies that have different algebraic features. The solution given by S5 is based on a wrong interpretation of the rate. The student misses the unit value (price of each chocolate). In addition, the result of the distribution is correct although the strategy followed is not. The remarkable aspect of S6's solution is the relationship between percentages and proportionality in the distribution.

From an expert epistemic point of view, the mathematical activity developed by students S1 and S2 to solve problem 1 is considered arithmetic, that is, algebraization level 0: no intensive objects are involved and operations are carried out just with extensive objects. Indeed, they operate on particular numbers (the amount of cans of red and yellow paint), using natural and numerical languages; the symbols "?"-in 


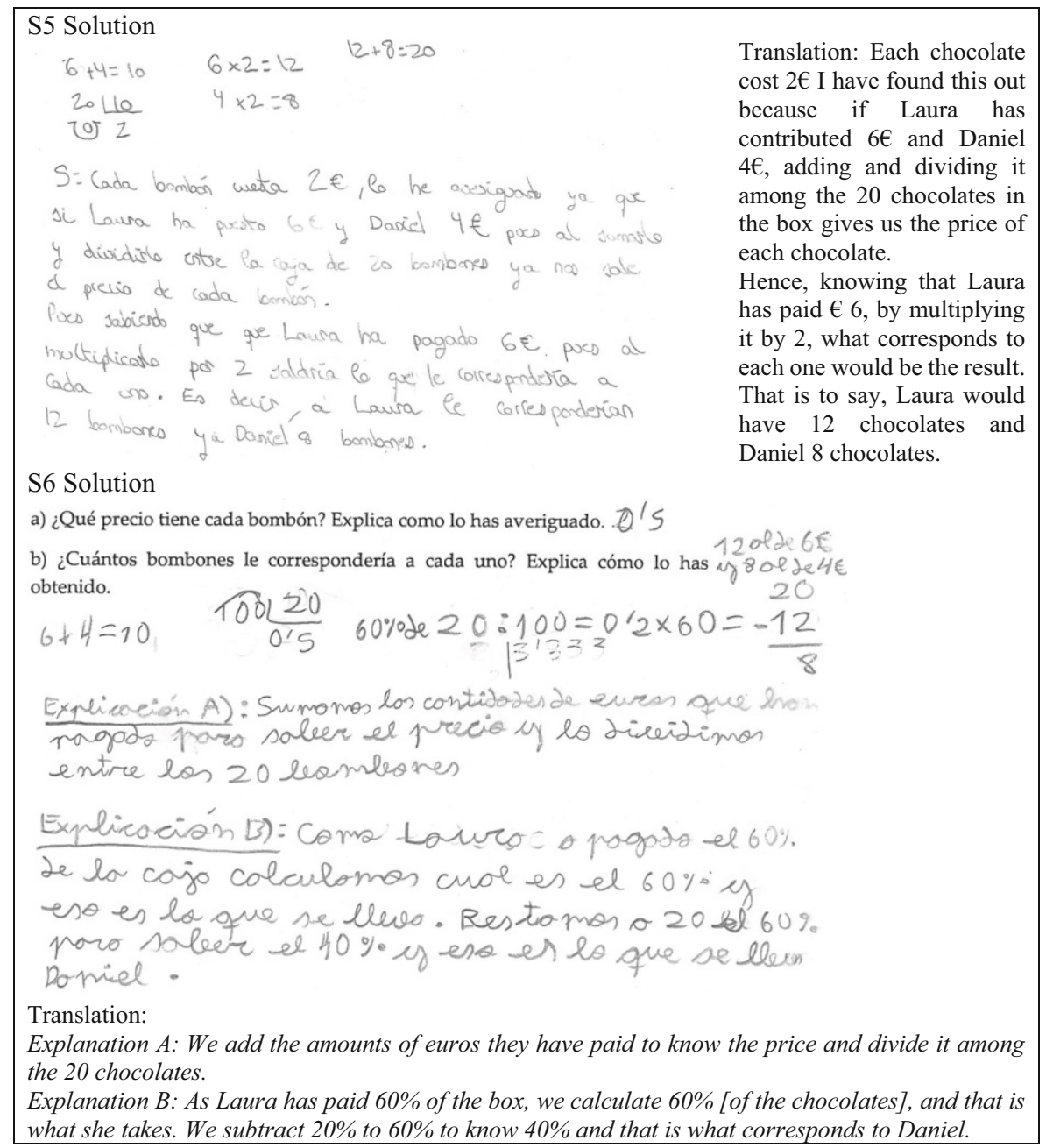

Fig. 5 Responses of students S4 and S5 to problem 2

the case of the student S1 - and the literal " $x$ " in the case of student S2, refer in both cases to an unknown value, but this value is obtained as a result of the operations on the particular numbers involved, so there is no presence of algebraic objects. S2 uses the doubling strategy (Tourniaire and Pulos 1985). She identifies the multiplicative relationship "twice as much red paint as yellow paint" (that represents in a diagram as " $\times 2$ "), which allows her to argue that Sofia will use 14 cans of red paint because this is twice the seven cans of yellow paint.

Student S3's solution relies on a building-up strategy. The mathematical activity developed is also considered of algebraization level 0; a natural, numeric and iconic language is used and one operates with particular values of the numbers of days and kilograms of food. The argument describes the strategy used by the student to solve the problem. Student S4 recognises the proportionality relationship and proposes 
a proportional equation, in which the ratios compare the kilograms of food with the number of days that chickens can eat. The student states "I have used the rule of three"; however, the intervention of the literal symbol to represent the unknown is the only algebraic feature that comes into play, since in order to find the value of the unknown, no explicit formulation nor solving of an equation of the form $A x=C$ is depicted. The student justifies its solution on the basis of the (intensive object) equivalence of fractions that appear in the proportionality relationship (which links to the proportionality table). Due to this, the algebraization degree of the student's activity would be proto-algebraic of level 1 according to the criteria of Godino et al. (2014).

S5's solution is associated with an algebraization level 0 since only arithmetic operations with natural numbers, and natural and numerical languages are involved in the student's answer. In the case of student S6, the use of the percentage concept to determine the number of chocolates that corresponds to each child, from the percentage of the box price they have paid, involves a greater degree of generality, hence, in terms of the algebraization levels model, this corresponds to level 1 . The argument to item (a) (explanation A) relies on the relation between the parts and the whole for the price of the box of chocolates. The argument for the second item establishes the relationship between what Laura paid towards the box of chocolates and what corresponds to her, and the complement to 100 of the percentages.

\subsection{Scoring Guidelines}

The a priori analysis of the primary education students' solutions (degree of correctness, recognition of the objects involved in the mathematical practices and assignment of the corresponding algebraization level) was carried out independently by the authors and then confronted in order to draw up the correctness guides.

The application of the correctness guidelines to the prospective teachers' response protocols was performed by the first author, and also independently by the second author when the interpretation of any of the answers was unclear. In these cases, the assignment of scores was discussed and resolved jointly by both authors. The categories for incorrect explanations given by the prospective teachers appear as a consequence of the analysis of their responses.

\subsubsection{Correctness Degree of Students' Solutions}

First, we asked the prospective teachers about the degree of correctness of the six students' responses. We decided to positively evaluate the partially correct or incomplete answers, so that the score given to the items was:

- 0 points if either the student's solution is incorrectly assessed, it is not justified, or the justification is not conclusive;

- 1 point if the student's answer is rightly assessed but the justification is not applicable;

- 2 points if the valuation of the student's answer and its justification are correct. 
Non-conclusive justifications are based on general observations that do not permit the determination of the assessment of the degree of correctness assigned to the student's response. For example, this category includes the answer of PT11 for the correction degree of S3: "Student S3 uses his imagination to find a solution to the problem, which I value in a very positive way", or the answer of PT9 for the correction degree of S4: "because the result is the expected one".

Within the non-applicable justifications given by the prospective teachers, we find two categories:

- Procedural justification, often based on the use or non-use of the rule of three. For example, PT4 points out that the answer given by student S1 is not correct since "the proper way [to solve the problem] would be to carry out a rule of three." In this same category is the justification of PT5 who, to ensure that the solution of student S4 is correct, says "he uses resources of their level, equality of fractions, rules of three and solving equations."

- Justification based on an expert solution or previous solution. In this category we find answers in which the prospective teacher justifies the degree of correctness of the student's solution based on the concordance with his own solution to the problem, or relying on the solution that another student has given to the problem and that the prospective teacher has previously assessed in terms of the procedure or strategy used. For example, PT7 points out that the answer given by student S4 is correct since "its result matches the one that I have obtained through the rule of three". In other cases, the correctness of the solutions of S4 and S6 are based on the agreement with the results obtained by S3 and S5, respectively. For example, PT37 states with respect to the answer given by S6 that "the solution of student S5 would be easier" (PT37).

\subsubsection{Identification of the Mathematical Objects Involved in Students' Solutions}

After assessing the degree of correctness of the solutions, prospective teachers should identify the types of languages, concepts, propositions, procedures and arguments they recognise in the answers given by the primary school students. We consider the following criteria to assess the relevance in the identification of mathematical objects:

- Not suitable (valued with 0 points). Prospective teacher identifies objects incorrectly or only identifies types of languages and some other object (usually procedures). We consider those responses in which the prospective teacher recognises the objects characteristic of the algebraization level they have previously assigned and not those that actually appear in the students' responses, also to be irrelevant. For example, PT11 identifies in a general way for problem 1 (S1 and S2): "the language used is natural and numerical and the concepts of sum and multiplication of natural numbers are recognised. The procedure followed is inductive."

- Almost suitable (1 point). The prospective teacher correctly identifies at least three types of objects (normally, languages, concepts and procedures). For example, 
Table 1 Identification of mathematical objects in the solutions of S5 and S6 (PT61)

\begin{tabular}{lllll}
\hline & Languages & Concepts & Properties & Procedures \\
\hline S5 & $\begin{array}{l}\text { Natural, numerical and } \\
\text { iconic }\end{array}$ & $\begin{array}{l}\text { Multiplication, } \\
\text { division }\end{array}$ & $\begin{array}{l}\text { Student does not use } \\
\text { any property }\end{array}$ & $\begin{array}{l}\text { Multiplication and } \\
\text { division algorithms }\end{array}$ \\
S6 & $\begin{array}{l}\text { Natural, numerical, } \\
\text { iconic and symbolic }\end{array}$ & Percentages & $\begin{array}{l}\text { Student does not use } \\
\text { any property }\end{array}$ & $\begin{array}{l}\text { Multiplication and } \\
\text { division algorithms }\end{array}$ \\
\hline
\end{tabular}

Table 2 Identification of the sequence of proportional quantities as a procedure in the solution of S3 (PT68)

\begin{tabular}{llllll}
\hline Days & 6 & 12 & 18 & 24 & 30 \\
\hline Kilograms & 3 & 6 & 9 & 12 & 15 \\
\hline
\end{tabular}

PT61 includes Table 1 where he summarizes the mathematical objects that he identifies in the solutions of S5 and S6.

- Suitable (2 points). The prospective teacher correctly identifies all the different objects in the solution given by the student. For example, PT68 identifies in a quite suitable way, the mathematical objects emerging from S3 solution. He provides Table 2 in order to highlight the relationship between days and kilograms stated by $\mathrm{S} 3$.

Languages: natural, numerical, symbolic, pictorial.

Concepts: sum of natural numbers, multiplication of natural numbers, rate dayskilograms of corn.

Proposition: every 30 days they consume $15 \mathrm{~kg}$ of food.

Argument: every 6 days they eat $3 \mathrm{~kg}$ of corn.

Procedure: student develops a sequence of additive relationships

\subsubsection{Recognition of Algebraization Levels in Students' Practices}

In order to assess the prospective teachers' recognition of algebraization levels in the students' mathematical practices, we compared them with the levels assigned by the researchers (detailed in Sect. 3.1). In this case, we did not find differentiated categories, since the arguments used by the prospective teachers are based on the degree of generality of the objects, the treatment applied to these objects, and the types of languages used, according to the level of algebrization they have assigned (whether the level allocated is adequate or not).

\section{Results}

\subsection{Assessing the Degree of Correctness of Students' Solutions}

Since the prospective teachers had to assess the responses of six students (two for each problem: S1 and S2, for problem 1, S3 and S4 for problem 2, S5 and S6 for 
Table 3 Correctness degree of the valuations $(N=88)$

\begin{tabular}{lllllll}
\hline Suitability & \multicolumn{5}{l}{ Frequencies in the correctness of the assessment of primary school students' responses } \\
& S1 & S2 & S3 & S4 & S5 & S6 \\
\hline 0 & $26(29.6)$ & $25(28.4)$ & $37(42.1)$ & $30(34.1)$ & $57(64.8)$ & $41(46.6)$ \\
1 & $22(25)$ & $22(25)$ & $23(26.1)$ & $35(39.8)$ & $22(25)$ & $30(34.1)$ \\
2 & $40(45.4)$ & $41(46.6)$ & $28(31.8)$ & $23(26.1)$ & $9(10.2)$ & $17(19.3)$ \\
\hline
\end{tabular}

Table 4 Types and frequencies of little or not suitable valuations of students' answers

\begin{tabular}{|c|c|c|c|c|c|c|c|}
\hline \multicolumn{2}{|c|}{ Relevance } & \multicolumn{6}{|c|}{ Primary school students' responses } \\
\hline & & \multirow{2}{*}{$\begin{array}{l}\mathrm{S} 1 \\
5\end{array}$} & \multirow{2}{*}{$\frac{\mathrm{S} 2}{3}$} & \multirow{2}{*}{$\frac{\mathrm{S} 3}{0}$} & \multirow{2}{*}{$\frac{\mathrm{S} 4}{0}$} & \multirow{2}{*}{$\frac{\text { S5 }}{12}$} & \multirow{2}{*}{$\frac{\text { S6 }}{9}$} \\
\hline 0 & Incorrect valuation & & & & & & \\
\hline & Correct but not justified valuation & 10 & 10 & 18 & 11 & 31 & 20 \\
\hline & Correct but not conclusive justification & 11 & 12 & 19 & 19 & 14 & 12 \\
\hline & Total & 26 & 25 & 37 & 30 & 57 & 41 \\
\hline \multirow[t]{3}{*}{1} & Based on prior or expert solution & 5 & 3 & 3 & 5 & 2 & 4 \\
\hline & Procedural justification & 17 & 19 & 20 & 30 & 20 & 26 \\
\hline & Total & 22 & 22 & 23 & 35 & 22 & 30 \\
\hline
\end{tabular}

problem 3), the maximum score they could achieve was 12 points. We observed that, although only one participant achieved the maximum score, 43 of the 88 prospective teachers $(48.9 \%)$ obtained 6 or more points, and hence they evaluated the students' answers in a somewhat appropriate way: these prospective teachers only scored 0 points for at most two of the students' solutions (usually that of S5 and S6). Moreover, of these 43 prospective teachers, $15(17.1 \%)$ obtained a score of 1 or 2 points in all the answers.

As we see in Table 3, the prospective teachers were more successful in assessing the degree of correctness in the responses of students S1 and S2 (less than 30\% of then responded in a non-suitable way in both cases). More difficulties arose when assessing the responses of students S5 and S6 to problem 3. These results can be better understood by looking at Table 4 and the prototypical examples of prospective teachers' responses shown below. Table 4 summarizes the results obtained in relation to the answers that are little or not suitable. For the non-suitable answers (valued with 0 points in Table 3) we distinguish the incorrect valuations from those that were correctly valued but not justified or non-conclusively justified. For the almost suitable assessment (valued with 1 point in Table 3), we discriminate the answers according to the types of non-applicable justifications indicated above.

As we can see, the two main reasons why an answer is scored as 0 are the absence of justification of their evaluation or a non-conclusive explanation. The responses of prospective teachers who incorrectly assess the responses of the students are less frequent. For instance, PT54 considers the response given by S1 correct and the answer given by $\mathrm{S} 2$ incorrect:

Both the procedure and the argument raised [by S1] are considered correct. As the problem says that the two girls want to paint their room of the same colour, the student argues that both should use the same number of cans of paint, so 
he/she makes the sum of the pots that he/she knows of one of the girls, Laura, and the result obtained from that sum is subtracted from the number used so far by the other girl, Sofia.

The procedure carried out by this student [S2] would be correct and would be well posed if we wanted to know twice the number of cans that Sofia uses, for that reason he/she uses the number of cans Laura uses since she thinks, that if the double of 3 is 6 , the cans Sophia uses must be twice 7, that is 14 . This is not correct, because the solution he/she gives us is not appropriate.

As we observe, PT54 does not identify the additive strategy of student S1 as erroneous, showing a severe lack of common knowledge about proportionality. In other cases, prospective teachers with two different solutions to the same problem (as in the case of S1 and S2) consider the apparently simpler answer as good. For example, PT1 states:

I think that the operations that the student [S1] has been taught about what the necessary amount of red paint would be, are suitable, thus being able to solve these in a clear and simple way and arriving at the solution easily and adequately.

The responses of prospective teachers who incorrectly assess the responses of S5 and S6, usually consider the procedure used by S5 to obtain the unit value (price of each chocolate), by dividing the price of the box by the number of chocolates in it, to be appropriate. That is the case of PT1 who asserts:

The answer [of S5 to item (a)] is correct, since the students have added the money that both have given and have found out what the price of the box of chocolates is, $10 €$. Then the student has divided those $10 €$ among the 20 chocolates in order to know how much each chocolate costs, obtaining $2 €$. Finally, he/she has multiplied the price of each chocolate by the money they have contributed to know how many chocolates correspond to each one: 12 and 8 , respectively.

The answer [from S6] to question (a) is incorrect, since the student has considered that each chocolate costs 0.5 , but the surprising thing is that the procedure to find the price of each chocolate is correct: the student has added the money and divided it between 20 to know how much each chocolate costs.

The most frequent justifications in the assessments of all students are of procedural type. In addition, we observe that prospective teachers have difficulties in analysing and evaluating non-usual resolution strategies to proportionality tasks. Such is the case of the answer given by student S3. For example, a type of recurrent evaluation in this sense is given by PT79 for the degree of correctness of S3's response.

The student [S3] has managed to reach the correct result, but without making a correct statement of the exercise. He has tried to perform the problem in a rudimentary way by counting six by six until the desired result is achieved instead of making a correct statement using a rule of 3 or another valid option. 
As we have observed, several prospective teachers consider the response of S3 inappropriate, assuring that "if they were larger numbers, another method should be applied to solve the problem", or describing it as "quite laborious and tricky to understand". In addition, a large number of them say that "to solve this type of problem it would be best to use the rule of three" when assessing the students' responses.

\subsection{Assessing the Identification of the Mathematical Objects Involved in Students' Solutions}

Taking into account the criteria established in Sect. 3.3, the maximum score that prospective teachers could obtain in this task was 12 points (two for each solution). The prospective teachers had great difficulty responding appropriately to this task:

- $32(36.4 \%)$ obtained exactly 0 points in this task. Of these, 27 prospective teachers only recognise the types of languages in the different solutions, and 5 prospective teachers identify the generic objects characteristic of the algebraization level that have been previously recognised and not those involved in the students' solution.

- 21 (23.9\% of the total) obtained between 1 and 6 points since they identified in some of the students' solutions some objects (frequently procedures) besides the languages.

- Of the 88 prospective teachers, only 35 (39.8\%) obtained more than 6 points and only one single prospective teacher achieved the maximum score (12 points). The same one also obtained the maximum score in the assessment of the correctness degree of students' solutions.

As we see in Table 5, there are no relevant differences in the valuations according to the students' responses. The activity in which it was more difficult for the prospective teachers to identify the mathematical objects was that of S3 $(52.3 \%$ only correctly identified the type of language at the most) and the one with the best average results was that of $\mathrm{S} 4$, although there was a greater number of relevant answers (8) in the analysis of S2 solution. These results are due to the fact that prospective teachers who identify objects in a somewhat pertinent manner (valued with 1 point) recognise in an appropriate way the types of language (natural, numerical, iconic, diagrammatic, and symbolic), concepts and procedures, being the propositions and arguments the least recognised objects. Many prospective teachers did not identify any concept in the activity of S3 or S5, or explicitly stated "the student does not use any concept" (PT29, among others).

Table 5 Frequencies (percentages) of the relevance degree in the recognition of objects for each student's response $(N=88)$

\begin{tabular}{lllllll}
\hline Score & \multicolumn{4}{l}{ Primary school students' responses } & & \\
& S1 & S2 & S3 & S4 & S5 & S6 \\
\hline 0 & $41(46.6)$ & $41(46.6)$ & $46(52.3)$ & $37(42.0)$ & $44(50)$ & $39(44.3)$ \\
1 & $41(46.6)$ & $39(44.3)$ & $37(42.0)$ & $46(52.3)$ & $42(47.7)$ & $46(52.3)$ \\
2 & $6(6.82)$ & $8(9.1)$ & $5(5.7)$ & $5(5.7)$ & $2(2.3)$ & $3(3.4)$ \\
\hline
\end{tabular}


As we have mentioned, only $56(63.6 \%)$ of the prospective teachers identified any object other than the languages involved in the students' practices. Several researchers state that teachers often focus on the algorithmic aspect, resorting to procedural arguments to justify their strategies of solving proportionality problems (Lamon 2007; Riley 2010). This lack of understanding about the development of proportional reasoning also motivates that, when it comes to analysing the responses of students, prospective teachers reveal conflicts to properly recognise the arguments that appear in them:

Both solutions [of S1 and S2] use a null argument, because they do not define the problem by not making any type of information collection of the different types of elements and the relationship that exists between them [... They do not really argue and give a final result to the solutions (PT46).

The response of PT46 on the absence of arguments in the solutions of S1 and S2, allows us to observe a poor and incomplete knowledge about the object argument.

We noted that in general, prospective teachers have great difficulty in identifying the arguments, to read between the lines and to see beyond what is written explicitly in the students' answers. They usually confuse argument with the intentionality of the practice or procedure. For example, PT32 identifies as argument in the practice of S5 "Argument: calculate how much each chocolate costs and how many correspond to each one". Other students confuse the argument used by the students in solving the problem, as an object involved in the students' activity, with the justification they give (as prospective teachers) to assess the degree of correctness of the primary school student's response. For example, PT79 includes in the configuration of objects of the answer of S3 "the argument used is quite poor and messy for the teacher." PT74 affirms with respect to student S1 "the argument is not appropriate, since it is founded by an erroneous procedure".

\subsection{Recognition of Algebraization Levels in Students' Practices}

Except for two prospective teachers who assigned in general "level 1 or 2 " to all the answers (PT28) and "levels 0 or 1" (PT29) without distinguishing the levels according to the students' practices, the other prospective teachers justified the algebraization level to the different solutions. As we see in Table 6, 56 of them $(63.6 \%)$ correctly recognised the algebraization level of the students' solutions in three or more of the cases, although only two correctly identified all the algebraization levels.

A priori, the assignment of algebraization levels to the solutions given by S3 and S5 should not pose difficulties for prospective teachers. In the case of the solutions given by $\mathrm{S} 1$ and $\mathrm{S} 2$, the challenge could arise in the use of the literal symbol. The difficulty to correctly identify the algebraization level of the S4 solution can consist of perceiving that no analytical calculation is developed with the literal symbol. On the other hand, in the case of S6, prospective teachers have to be aware of the generality degree that the use of percentages as a specific way of describing multiplicative comparisons, entails. 
Table 6 Success degree in the recognition of algebraization levels $(N=88)$

\begin{tabular}{lllllll}
\hline & \multicolumn{6}{l}{ Number of correct valuations in the algebraization level of the practices } \\
& 1 & 2 & 3 & 4 & 5 & 6 \\
\hline Frequencies (per- & 16 & 12 & 24 & 21 & 9 & 2 \\
centages) & $(18.2)$ & $(13.6)$ & $(27.3)$ & $(23.9)$ & $(11.2)$ & $(2.3)$ \\
\hline
\end{tabular}

Table 7 Absolute frequencies (percentages) in the assignment of algebraization levels to the students' solutions $(N=88)$

\begin{tabular}{lllll}
\hline Students' solutions & No answer & Level 0 & Level 1 & Level 2 \\
\hline S1 & $2(2.3)$ & $63(71.6)$ & $15(17.1)$ & $6(6.8)$ \\
S2 & $1(1.1)$ & $25(28.4)$ & $45(51.1)$ & $15(17.1)$ \\
S3 & $2(2.3)$ & $60(68.2)$ & $17(19.3)$ & $7(7.9)$ \\
S4 & $3(3.4)$ & $6(6.8)$ & $22(25)$ & $55(62.5)$ \\
S5 & $5(5.7)$ & $59(67.1)$ & $19(21.6)$ & $8(9.1)$ \\
S6 & $6(6.8)$ & $35(39.8)$ & $35(39.8)$ & $10(1.1)$ \\
\hline
\end{tabular}

In Table 7, we show the frequencies obtained in the recognition of the algebraization levels for each of the solutions given by primary school students. We emphasize in italics the frequencies corresponding to the correct assignment.

We observed that the prospective teachers were considerably successful in correctly identifying the algebraization level in the solutions given by students S1 (71.6\%), S3 (68.2\%) and S5 (67.1\%). All these solutions correspond to mathematical activities of arithmetic character. They had greater difficulty to correctly assign the algebraization level 0 in the case of S2 (only $28.4 \%$ did it appropriately), which was mostly $(51.1 \%)$ valued with algebraization level 1 , maybe due to the presence of the literal symbol. In the case of proto-algebraic activities (level 1) developed by student S4 (correct in 25\% of the cases) and S6 (correct in $39.8 \%$ of the cases), most prospective teachers $(62.5 \%$ of the responses) associated level 2 to the $\mathrm{S} 4$ solution, referring to the rule of three as a procedure. In the case of the solution given by S6, $39.8 \%$ of the prospective teachers did not identify the generality degree involved in the use of percentages and consequently assigned arithmetic character (level 0) to the mathematical activity of this student.

It is important that prospective teachers identify the different uses of the literal symbol as a placeholder or unknown, identifying when an analytical calculation intervenes and when it does not. The procedure of the rule of three is associated to the approach of an equation of type $\mathrm{A} x=\mathrm{B}$ and the consequent clearing of the unknown (algebraization level 2). For instance, PT42 correctly identifies level 1 in the S4 solution, stating "I consider that the algebraization level used is level 1, because regardless of the fact that a rule of 3 is used, there is an unknown that has not yet been cleared." In PT42's response, there is some confusion with the term rule of three, something that unfortunately is common among prospective teachers. PT72 also recognises the absence of syntactic calculation with the unknown, and hence assigns algebraization level 1 to $\mathrm{S} 4$ solution: 
Algebraization level 1 [of the solution given by S4]. Although the student indicates in their argument that he will use a rule of 3 , he did not. The student enters the " $\mathrm{x}$ " symbol as an unknown variable, but at no time uses this rule of three. He makes the solution through equivalent fractions and the multiplication algorithm since he has found that in 30 days there are 5 times 6 days, and therefore multiplies the $3 \mathrm{~kg}$ that they eat in 6 days by 5 .

\subsection{Correlational Analysis}

We have calculated the correlations between the variables $\mathrm{A}, \mathrm{B}$ and $\mathrm{C}$ relating to the score achieved for the degree of correctness of the students' solution (question $a$ ), objects identification (question $b$ ) and algebraization level assignment (question $c$ ), respectively. These variables are ordinal in nature, so it is pertinent to use Spearman's correlation coefficient. The correlation between A and B is 0.25 ; that of A with $\mathrm{C}, 0.37$; and that of $\mathrm{B}$ with $\mathrm{C}, 0.14$. It is observed that, although the correlation between $\mathrm{A}$ and $\mathrm{B}$ is significantly different from zero at 0.05 level, and that of $\mathrm{A}$ with $\mathrm{C}$ at 0.01 level, these correlations are small. In the case of the correlation of $\mathrm{B}$ with $\mathrm{C}$ it is not significant $(p=0.202)$. The knowledge required to assess the degree of correctness of the students' solution corresponds to common content knowledge (solving primary school problems and comparing their solutions with those given by the students). In contrast, responses to questions (b) and (c) involve specialised content knowledge (identification of mathematical objects and assignment of algebraization levels). The low degrees of association between variable $\mathrm{A}$ and variables $\mathrm{B}$ and $\mathrm{C}$, suggest that developing this kind of specialised content knowledge requires the implementation of more specific training actions.

\section{Discussion and Conclusion}

An important goal in mathematics teachers' education programs is the development of teachers' ability to interpret students' mathematical thinking, especially, while solving problems (Fernández et al. 2013). In this sense, we consider that the instrument used in this research could enhance teachers' ability to analyse the students' written work in mathematical tasks. In particular, to interpret different solution strategies in a problem by describing the system of operative and discursive practices performed by the students (personal meaning), and determining the network of objects and processes emerging from the system of such practices (cognitive configuration), can help to "identify the mathematical elements of problems that foster proportional reasoning breaking down the mathematics that define the problem and recognising the manner in which the mathematical elements that characterize the problem are present or not in the student's answer" (Llinares 2013, p. 80).

Another important and original characteristic of our research instrument is that it is elaborated from the research based on the algebraization levels model. The identification of the algebraization levels of the practices developed by primary school students allows teachers: (a) to become aware that the algebraic character 
corresponds not to the task itself, but to the mathematical activity that is carried out, (b) to understand its semiotic complexity and (b) to explain the learning difficulties.

The competence of cognitive analysis of mathematical knowledge for teaching proportionality, which has focused our attention in this paper, allows prospective teachers to make a microscopic analysis of students' responses, which goes beyond properly recognising the correct and incorrect students' answers. This is achieved by identifying the concepts, properties and procedures involved, and the arguments that are made ostensive through a variety of languages, as well as discriminating more or less algebraic objects when they attend the students' solutions to proportionality tasks.

Next, we respond to the research questions raised in this study:

(1) How do prospective teachers analyse and justify the degree of correctness of the solutions given by primary school students to proportionality problems?

In general, prospective teachers appropriately evaluate the correctness degree of students' solutions. However, their interpretations of students' answers mainly rely on the description of the procedures and not on the meanings (Fernández et al. 2013). In addition, we observe that prospective teachers have difficulties in analysing and evaluating non-usual resolution strategies to proportionality tasks. The incorrect assessments of the students' responses usually do not identify the constant sum incorrect strategy used by S1 or consider the responses of S3 or S6 inappropriate as "quite laborious" or "tricky to understand". Prospective teachers defend the rule of three as the "best strategy" to apply in proportionality tasks when assessing the students' responses.

(2) What mathematical elements (languages, concepts, properties, procedures and arguments) do prospective teachers identify in the solutions proposed by primary school students?

Prospective teachers had great difficulties in identifying the mathematical objects (especially propositions and arguments) in the solutions elaborated by the primary school students. This could be related with the lack of knowledge of the nature of the mathematical objects. This unawareness could also explain why prospective teachers confound procedure with concept, or proposition and argument with procedure. To this respect, prospective teachers showed great limitations to recognise arguments other than deductive or those based on arithmetic properties.

(3) Based on this identification, are prospective teachers able to assign levels of algebraic reasoning to the different solutions analysed?

Despite the previous fact, prospective teachers properly recognised the algebraization levels in students' practices (even though these levels are defined in terms of the objects, meanings and processes emerging in the mathematical activity). The major difficulty arose with the solutions proposed by S2 and S4: in the case of the solutions given by S2, the complexity appeared in the use of the literal symbol, and in the case of S4 solution, the challenge consisted of perceiving that no analytical calculation is developed with the literal symbol. This may be because prospective teachers based their choice of the algebraic degree of the students' practices upon 
the strategy followed, and the fact that they have not managed to correctly appreciate the role of the literal symbols and the analytical calculus in the algebraic practice.

To ensure that prospective teachers are able to respond to students' errors, teacher education programs should develop the understanding of the conceptual, propositional and argumentative components of proportional reasoning, to promote the flexibility in the use of multiple methods to solve the problems that involve proportionality (Buforn et al. 2018), and to facilitate ample opportunities for prospective teachers to analyse student responses, providing them with tools to guide their interpretation.

We think that our results provide additional valuable information for the design of materials in teacher education programs that consider the characteristics of prospective teachers' learning and their understanding of proportional reasoning. In particular, the type of instrument used in this research could be adapted to design teaching material focused on the development of prospective teachers' competences to analyse students' written work. However, we mention some aspects, based on our findings that should be considered in the design and implementation of new research, to improve the results obtained with this training intervention.

The fact that prospective teachers' interpretations of students' responses are based primarily on the description of the procedures (use or non-use of the "rule of three") could be explained, as previous works of research suggest, by the emphasis on the routine solving procedure (rule memorization and rote computations) that traditional instruction places on teaching and learning proportionality (Arican 2018; Lamon 2007; Riley 2010). Hence, the formative process should include specific sessions focusing on proportional reasoning in which prospective teachers are introduced to the different forms of reasoning that can be applied in proportionality situations. To develop proportional reasoning, teachers should appreciate students' additive strategies and build on these to promote intuitive multiplicative reasoning. Moreover, to correctly address students' misconceptions, teachers should value certain methods as more effective for specific problems, supported by the recognition of the correspondence relationship between quantities.

Prospective teachers have limitations in recognising and differentiating the mathematical objects (concepts, propositions, arguments) emerging from students' solutions. They have great difficulties in identifying the arguments (which they usually confuse with the intentionality of the practice or procedure) and to read beyond what is written explicitly in the students' answers. This could prevent prospective teachers from identifying evidence of proportional reasoning in their answers. In order for prospective teachers to know the argumentation forms and to construe the argument used explicitly or implicitly by their students when solving proportionality tasks, it is important to highlight in their previous instruction the properties that characterize the proportionality relationship (the constant of proportionality, the additive and homogeneous properties of the linear function).

Discrepancies between how prospective teachers interpret students' answers could be related to the characteristics of the problem used and the type of strategy used (building-up strategy, which is not a common strategy, rule of three and the use of ratios). Moreover, as the difficulties in the recognition of the algebraization levels in students' practices arose with the distinction of the uses of the literal symbol, 
the identification of the analytical calculation performed on the unknowns, and the generality degree involved in the use of percentages, it is necessary to delve more deeply into the algebraic character of mathematical activity, considering the types of objects, representations and generalization processes arising from mathematical practices.

An improvement of the results also requires prospective teachers to gain familiarity with the theoretical-methodological tools (onto-semiotic configuration and elementary algebraic reasoning) beforehand. An increase of the time allocated to the formative intervention will permit extending the number and variety of situations-problems proposed, their solutions and discussion. In this sense, we mention that prospective teachers acknowledged feeling more insecure and less trained (in general, through their undergraduate studies) in facing the tasks solved by students than in the resolution and analysis of tasks solved by themselves.

Moreover, it is important to study to what extent prospective teachers take into account the analysis developed in this formative intervention to propose teaching decisions (Buforn et al. 2020). To this end, the research instrument should be enhanced by including decision making on how to respond to the students' wrong answers.

Funding Research carried out as part of the research project, PID2019-105601 GB-I00/AEI/10.13039/5011 00011033, with support from the FQM-126 Research Group (Junta de Andalucía, Spain).

Funding Funding for open access charge: Universidad de Granada/CBUA

Open Access This article is licensed under a Creative Commons Attribution 4.0 International License, which permits use, sharing, adaptation, distribution and reproduction in any medium or format, as long as you give appropriate credit to the original author(s) and the source, provide a link to the Creative Commons licence, and indicate if changes were made. The images or other third party material in this article are included in the article's Creative Commons licence, unless indicated otherwise in a credit line to the material. If material is not included in the article's Creative Commons licence and your intended use is not permitted by statutory regulation or exceeds the permitted use, you will need to obtain permission directly from the copyright holder. To view a copy of this licence, visit http://creativecommons.org/licenses/by/4. $0 \%$

Conflict of interest M. Burgos and J.D. Godino declarethat they have no competing interests.

\section{References}

Aké, L., Godino, J.D., Gonzato, M., \& Wilhelmi, M. R. (2013). Proto-algebraic levels of mathematical thinking. In A. M. Lindmeier \& A. Heinze (Eds.), Proceedings of the 37th Conference of the International Group for the Psychology of Mathematics Education (Vol. 2, pp. 1-8). Kiel: PME.

Arican, M. (2018). Preservice middle and high school mathematics teachers' strategies when solving proportion problems. International Journal of Science and Mathematics Education, 16(2), 315-335. https://doi.org/10.1007/s10763-016-9775-1.

Artigue, M. (1989). Ingénierie didactique. Recherches en Didactique des Mathématiques, 9(3), 281-308.

Ball, D. L., \& Bass, H. (2009). With an eye on the mathematical horizont: knowing mathematics for teaching to learnes' mathematical futures. Paper presented at the $43^{\mathrm{Rd}}$ Jahrestagung Für Didaktik Der Mathematik, Oldenburg.

Barnhart, T., \& van Es, E. (2015). Studying teacher noticing: examining the relationship among pre-service science teachers' ability to attend, analyze and respond to student thinking. Teaching and Teacher Education, 45, 83-93. https://doi.org/10.1016/j.tate.2014.09.005. 
Bartell, T.G., Webel, C., Bowen, B., \& Dyson, N. (2013). Prospective teacher learning: recognising evidence of conceptual understanding. Journal of Mathematics Teacher Education, 16(1), 57-79. https:// doi.org/10.1007/s10857-012-9205-4.

Ben-Chaim, D., Keret, Y., \& Ilany, B. (2012). Ratio and proportion: research and teaching in mathematics teachers' education. Rotterdam: Sense Publisher.

Berk, D., Taber, S.B., Gorowara, C.C., \& Petzl, C. (2009). Developing prospective elementary teachers' flexibility in the domain of proportional reasoning. Mathematical Thinking and Learning, 11(3), 113-135. https://doi.org/10.1080/10986060903022714.

Blömeke, S., Gustafsson, J.-E., \& Shavelson, R. J. (2015). Beyond dichotomies. Competence viewed as a continuum. Zeitschrift für Psychologie, 223(1), 3-13. https://doi.org/10.1027/2151-2604/a000194.

Breda, A., Pino-Fan, L. R., \& Font, V. (2017). Meta didactic-mathematical knowledge of teachers: criteria for the reflection and assessment on teaching practice. Eurasia Journal of Mathematics, Science and Technology Education, 13(6), 1893-1918. https://doi.org/10.12973/eurasia.2017.01207a.

Brousseau, G. (1997). The theory of didactical situations in mathematics. Dordrecht: Kluwer.

Buforn, A., Llinares, S., \& Fernández, C. (2018). Características del conocimiento de los estudiantes para maestro españoles en relación con la fracción, razón y proporción. Revista Mexicana de Investigación Educativa, 23, 229-251.

Buforn, A., Llinares, S., Fernández, C., Coles, A., \& Brown, L. (2020). Pre-service teachers' knowledge of the unitizing process in recognising students' reasoning to propose teaching decisions. International Journal of Mathematical Education in Science and Technology. https://doi.org/10.1080/0020739X. 2020.1777333

Burgos, M., \& Godino, J.D. (2018). Recognising algebraization levels in an inverse pro,ortionality task by prospective secondary school mathematics teachers. Proceedings of EDULEARN18 Conference, Mallorca. (pp. 2483-2491).

Burgos, M., Beltrán-Pellicer, P., Giacomone, B., \& Godino, J. D. (2018). Prospective mathematics teachers' knowledge and competence analysing proportionality tasks. Educação E Pesquisa, 44, 1-22. https:// doi.org/10.1590/S1678-4634201844182013.

Burgos, M., Godino, J.D., \& Rivas, M. (2019). Epistemic and cognitive analysis of proportionality tasks from the algebraization levels perspective. Acta Scientiae, 21(4), 63-81. https://doi.org/10.17648/ acta.scientiae.6552.

Carraher, D. W., \& Schliemann, A. D. (2007). Early algebra and algebraic reasoning. In F. K. Lester (Ed.), Second handbook of research on mathematics teaching and learning: a project of the national council of teachers of mathematics (pp. 669-706). Reston: NCTM e IAP.

Chapman, O. (2014). Overall commentary: understanding and changing mathematics teachers. In J.J. Lo, K. R. Leatham \& L. R. Van Zoest (Eds.), Research trends in mathematics teacher education (pp. 295-309). Dordrecht: Springer.

Cobb, P., Confrey, J., diSessa, A., Lehrer, R., \& Schauble, L. (2003). Design experiments in educational research. Educational Researcher, 32(1), 9-13.

Cramer, K., \& Post, T. (1993). Connecting research to teaching proportional reasoning. Mathematics Teacher, 86(5), 404-407.

Depaepe, F., Verschaffel, L., \& Star, J. (2020). Expertise in developing students' expertise in mathematics: bridging teachers' professional knowledge and instructional quality. ZDM. The International Journal on Mathematics Education, 52(2), 179-192. https://doi.org/10.1007/s11858-020-01148-8.

Fernández, C., Llinares, S., \& Valls, J. (2013). Primary school teacher's noticing of students' mathematical thinking in problem solving. The Mathematics Enthusiast, 10(1), 441-468.

Font, V., Godino, J.D., \& Gallardo, J. (2013). The emergence of objects from mathematical practices. Educational Studies in Mathematics, 82, 97-124. https://doi.org/10.1007/s10649-012-9411-0.

Godino, J. D., \& Batanero, C. (1996). Institutional and personal meaning of mathematical objects. Journal für Mathematik-Didaktik, 17, 99-121.

Godino, J.D., Batanero, C., \& Font, V. (2007). The onto-semiotic approach to research in mathematics education. ZDM. The International Journal on Mathematics Education, 39(1-2), 127-135. https:// doi.org/10.1007/s11858-006-0004-1.

Godino, J. D., Batanero, C., Contreras, A., Estepa, A., Lacasta, E., \& Wilhelmi, M. R. (2013). Didactic engineering as design-based research in mathematics education. Proceedings CERME8, Turkey. http:// cerme8.metu.edu.tr/wgpapers/WG16/WG16_Godino.pdf. Accessed 24 Sept 2021.

Godino, J.D., Aké, L., Gonzato, M., \& Wilhelmi, M. R. (2014). Niveles de algebrización de la actividad matemática escolar. Implicaciones para la formación de maestros. Enseñanza de las Ciencias, 32(1), 199-219. 
Godino, J. D., Giacomone, B., Batanero, C., \& Font, V. (2017). Enfoque ontosemiótico de los conocimientos y competencias del profesor de matemáticas. Bolema, 31(57), 90-113.

Hill, H.C., Ball, D. L., \& Schilling, S. G. (2008). Unpacking pedagogical content knowledge: conceptualizing and measuring teachers' topic-specific knowledge of students. Journal for Research in Mathematics Education, 39, 372-400.

Ivars, P., Fernández, C., Llinares, S., \& Choy, B.H. (2018). Enhancing noticing: using a hypothetical learning trajectory to improve pre-service primary teachers' professional discourse. Eurasia Journal of Mathematics, Science and Technology Education, 14(11), em1599. https://doi.org/10.29333/ejmste/ 93421.

Jacobs, V.R., Lamb, L.C., \& Philipp, R. (2010). Professional noticing of children's mathematical thinking. Journal for Research in Mathematics Education, 41(2), 169-202. https://doi.org/10.5951/ jresematheduc.41.2.0169.

Kieran, C. (2004). Algebraic thinking in the early grades: What is it. The Mathematics Educator, 18(1), $139-151$.

Kurt, W. (1992). Proportionen und antiproportionen. Untersuchungen zum funktionalen Denken von Schülern. Journal für Mathematik-Didaktik, 13, 311-343.

Lamon, S. (2007). Rational number and proportional reasoning: toward a theoretical framework for research. In F. K. Lester (Ed.), Second handbook of research on mathematics teaching and learning (pp. 629-667). Charlotte: NCTM.

Langrall, C. W., \& Swafford, J. (2000). Three balloons for two dollars: developing proportional reasoning. Mathematics Teaching in the Middle School, 6(4), 254-261.

Lesh, R., Post, T., \& Behr, M. (1988). Proportional reasoning. In J. Hiebert \& M. Behr (Eds.), Number concepts and operations for the middle grades (pp. 93-118). Reston: NCTM.

Lichti, M., \& Roth, J. (2019). Functional thinking-A three-dimensional construct? Journal für Mathematik-Didaktik, 40, 169-195. https://doi.org/10.1007/s13138-019-00141-3.

Livy, S., \& Vale, C. (2011). First year pre-service teachers' mathematical content knowledge: methods of solution for a ratio question. Mathematics Teacher Education and Development, 13(2), 22-43.

Llinares, S. (2013). Professional noticing: a component of the mathematics teacher's professional practice. Sisyphus, Journal of Education, 1(3), 76-93.

Misailidou, C., \& Williams, J. (2002). "Ratio": Raising teachers' awareness of children's thinking. Paper presented at the 2nd ICMI. http:/www.math.uoc.gr/ ictm2/Proceedings/pap143.pdf (Created 16 Feb 2010). Accessed 24 Sept 2021.

Misailidou, C., \& Williams, J. (2003). Diagnostic assessment of children's proportional reasoning. Journal of Mathematical Behaviour, 22(3), 335-368.

Modestou, M., \& Gagatsis, A. (2010). Cognitive and metacognitive aspects of proportional reasoning. Journal of Mathematical Thinking and Learning, 12(1), 36-53. https://doi.org/10.1080/ 10986060903465822.

Pino-Fan, L., Assis, A., \& Castro, W.F. (2015). Towards a methodology for the characterization of teachers' didactic-mathematical knowledge. EURASIA Journal of Mathematics, Science \& Technology Education, 11(6), 1429-1456.

Riley, K. J. (2010). Teachers' understanding of proportional reasoning. In P. Brosnan, D. B. Erchick \& L. Flevares (Eds.), Proceedings of the 32nd annual meeting of the North American Chapter of the International Group for the Psychology of Mathematics Education (Vol. 6, pp. 1055-1061). Columbus: The Ohio State University.

Rivas, M., Godino J.D., \& Castro, W.F. (2012). Desarrollo del conocimiento para la enseñanza de la proporcionalidad en futuros profesores de primaria. Bolema, 26(42B), 559-588.

Scheiner, T., Montes, M.A., Godino, J.D., Carrillo, J., \& Pino-Fan, L. (2019). What makes mathematics teacher knowledge specialized? Offering alternative views. International Journal of Science and Mathematics Education, 17, 153-172. https://doi.org/10.1007/s10763-017-9859-6.

Shulman, L.S. (1986). Those who understand: Knowledge growth in teaching. Educational Researcher, 15, 4-14.

Simpson, A., \& Haltiwanger, L. (2017). This is the first time I've done this: exploring secondary prospective mathematics teachers' noticing of students' mathematical thinking. Journal of Mathematics Teacher Education, 20(4), 335-355. https://doi.org/10.1007/s10857-016-9352-0.

Son, J. (2013). How preservice teachers interpret and respond to student errors: ratio and proportion in similar rectangles. Educational Studies in Mathematics, 84, 49-70. https://doi.org/10.1007/s10649013-9475-5.

Tourniaire, F., \& Pulos, S. (1985). Proportional reasoning: A review of the literature. Educational Studies in Mathematics, 16, 181-204. 
Van Dooren, W., De Bock, D., \& Verschaffel, L. (2010). From addition to multiplication ... and back: the development of students' additive and multiplicative reasoning skills. Cognition and Instruction, 28(3), 360-381. https://doi.org/10.1080/07370008.2010.488306. 